17 MacCallum AG, Stafford PJ, Jones C, Vincent R, Perez-Avila C, Chamberlain $\mathrm{DA}$. Reduction in hospital time to thrombolytic therapy by audit of policy guidelines. Eur Heart F 1990;11 (suppl F):48-52.

18 Rawles JN, Haites NE. Patient and general practitioner delays in acute myocardial infarction. BMF 1988;296:882-4.

19 Ridker P, Buring J, Manson J, Goldhaber S, Hennekens C. Time to presentation for acute MI in the US Physicians' Health Study. I Am Coll Cardiol 1990;15(suppl 2):167A.

20 Weaver WD, Eisenberg MS, Martin JS, Litwin PE, Schaeffer SM, Ho MT, et al. Myocardial infarction triage and intervention project - phase I: patient characteristics and feasibility of prehospital initiation of thrombolytic therapy. F Am Coll Cardiol 1990;15:925-30.

21 European Myocardial Infarction Project (EMIP) Subcommittee. Potentia time saving with pre-hospital intervention in acute myocardial infarction Eur Heart f 1988;9:118-24.

22 Burns JMA, Hogg KJ, Rae AP, Hillis WS, Dunn PG. Impact of a policy of direct admission to a coronary care unit on use of thrombolytic therapy. Br Heart f 1989;61:322-5.

\title{
Irritable bowel syndrome in the general population
}

\author{
Roger Jones, Susan Lydeard
}

\section{Abstract}

Objective-To determine the prevalence of symptoms compatible with a clinical diagnosis of irritable bowel syndrome in the general population.

Design-Validated postal questionnaire sent to 2280 subjects randomly selected in 10 year age bands from the lists of eight general practitioners. The Manning criteria were used to define irritable bowel syndrome.

Setting-Urban population in Southampton and mixed urban-rural population in Andover, Hampshire.

Results -A response of $71 \%$ yielded 1620 questionnaires for analysis, of which $412(25 \%)$ reported more than six episodes of abdominal pain in the preceding year, with $350(22 \%)$ reporting symptoms consistent with the diagnosis of irritable bowel syndrome. The male: female ratio was $1: 1.38$. More subjects with irritable bowel syndrome had constipation and diarrhoea and $35 \%$ with the syndrome reported rectal bleeding compared with an overall prevalence of $20 \%$. Other symptoms and conditions including heartburn, dyspepsia, flushing, palpitations, migraine, and urinary symptoms were significantly more common in the group with irritable bowel syndrome. Abdominal pain in childhood was more common in the subjects with irritable bowel syndrome $(12 \%)$ than without $(3 \%)$. One third of the group with irritable bowel syndrome had sought medical advice during the study period (male: female ratio 1:1.21); consultation behaviour was influenced by age and the presence of associated symptoms, varied considerably among patients registered with different general practitioners, and was poorly correlated with symptom severity.

Conclusion-Symptoms consistent with a diagnosis of irritable bowel syndrome are present in almost one quarter of the general population and tend to be associated with a number of other complaints and conditions, some of which may reflect smooth muscle dysfunction.

University of

Southampton,

Southampton

Roger Jones, FRCGP, senior

lecturer in primary medical

care

Susan Lydeard, BSC, research officer

Correspondence to:

Professor Roger Jones, Division of Primary Health Care, Medical School, Newcastle upon Tyne NE2 4HH.

BMF 1992;304:87-90

\section{Introduction}

The irritable bowel syndrome is the commonest functional gastrointestinal disorder seen in both primary and secondary care, ${ }^{12}$ and studies have shown that symptom complexes compatible with the clinical diagnosis of irritable bowel syndrome may be present in up to $30 \%$ of the general population. ${ }^{34}$ Most people with gastrointestinal symptoms never consult doctors about them ${ }^{s}$; previous studies on dyspepsia, for example, have shown that concern about the possible serious significance of symptoms is a major determinant of consultation behaviour. ${ }^{6}$ This is likely to be true for irritable bowel syndrome also.

Traditionally, irritable bowel syndrome has been a diagnosis of exclusion, made only after organic disease has been ruled out by investigation. Unnecessary investigations not only involve costs to the health services but also may increase diagnostic uncertainty and heighten patients' anxiety. In an attempt at greater precision, Manning and his coworkers reported the prevalence of 15 symptoms in irritable bowel syndrome and compared these with symptoms in patients with organic disease. ${ }^{7}$ They concluded that six cardinal symptoms discriminated the painful variant of irritable bowel syndrome from organic bowel disease. The more of these six symptoms that were present, the more likely it was that the patients had irritable bowel syndrome. Subsequently Thompson examined the discriminatory value of four symptoms - abdominal pain relieved by defecation, abdominal distension, and both looser and more frequent bowel movements with the onset of pain - and concluded that if two or more of these symptoms are present irritable bowel syndrome could be discriminated from peptic ulcer or organic bowel disease. ${ }^{8}$ Talley and colleagues have evaluated the reliability and discriminatory value of the Manning criteria in irritable bowel syndrome by using an objective self report questionnaire. ${ }^{9}$ Their findings suggest that these criteria can discriminate subjects with all forms of the syndrome from healthy controls and also from patients with organic gastrointestinal disease, although a recent study has cast some doubt on the diagnostic utility of the Manning criteria in men. ${ }^{10}$

There is also interesting evidence of disease associations with irritable bowel syndrome. A substantial number of patients also have abnormalities of bladder detrusor muscle function," and asssociations with a variety of urinary and gynaecological symptoms and with headache have been noted..$^{12}$ Most recently, patients with irritable bowel syndrome and without respiratory symptoms have been shown to have abnormally responsive airways after methacholine challenge, compared with normal controls and patients with organic bowel disease. ${ }^{14}$ The possibility that a generalised smooth muscle abnormality underlies all these conditions is a subject of considerable research and potential therapeutic interest.

Irritable bowel symptoms are common in the general population and in patients with organic disease, ${ }^{15}$ and the predictive value of any criteria will vary according to the prevalence of the disease in the population being assessed. Most people with symptoms will not present for medical care and it is possible that the symptomatology of presenting and non-presenting patients is different. ${ }^{34}$ Heaton's group, for example, has recently reported more severe abnormalities of bowel function, as well as more severe pain, in outpatients with irritable bowel syndrome compared with subjects with symptoms of irritable bowel syndrome identified in a community survey who had not sought medical attention. ${ }^{16}$ Other reports, however, have suggested that it is more likely that sociocultural factors, rather than the type or severity of symptoms, lead to differential health seeking behaviour in those suffering from irritable bowel syndrome, ${ }^{17-20}$ suggesting that the 
Manning criteria will remain valid in community studies.

Previous studies of the prevalence of functional bowel disorders have been published, but the samples from which this information is derived have not been representative of the general population. ${ }^{34} \mathrm{We}$ set out to determine the prevalence and pattern of functional bowel disorders in the general population by obtaining a random sample of adults from lists of patients registered with general practitioners working in the south of England and to describe the association between these symptoms and other disorders that might have a basis in smooth muscle dysfunction.

\section{Methods}

A questionnaire was developed, based on three previously published instruments, ${ }^{347}$ designed to obtain information about abdominal pain and bowel symptoms with particular reference to Manning et al's criteria.? After basic demographic information was collected questions were asked about experience and frequency of abdominal pain during the past year and the association of the pain with the timing and frequency of bowel movements and with abdominal bloating. Questions about incomplete evacuation, stool consistency, and straining at stool followed, with inquiry about the passage of blood or mucus rectally. Information about contact with the patient's general practitioner was followed by a list of questions about the presence of other specific symptoms including flushing, sweating, migraine, urinary symptoms, gynaecological problems, backache, tiredness, and asthma.

The questionnaire was validated and shown to be reliable in a pilot study conducted in the authors' practice, in which 100 questionnaires were distributed to a randomly selected group of patients aged 20-90. Over $80 \%$ of questionnaires were returned and half the respondents were sent a second questionnaire to determine repeatability. Half of the non-responders were telephoned or interviewed to determine validity of the questionnaire. Repeatability and validity rates in excess of $95 \%$ were obtained from this pilot study.

The questionnaires were then sent by post to a sample of 2280 adults aged 20-90, selected from the lists of eight general practitioners working in two health centres in Andover and Southampton, both in southern England. The sampling was performed by identifying all registered patients in each 10 year age band, allocating each a sequential number, and taking a random sample of one in five with tables of random numbers. In this way the number of study subjects in each age band reflected the proportion of people of that age in the general population. This method had been used in a previous study on dyspepsia and was found to generate a sample of patients whose demographic characteristics were representative of those of the geographical area in which the practice was situated.

The questionnaire was accompanied by a letter signed by the patient's own general practitioner, and a single reminder was sent to subjects who did not return the first questionnaire. The questionnaires were coded for analysis, and data handling and statistical tests were performed with SPSS PC computer software.

Irritable bowel syndrome was defined as abdominal pain on more than six occasions in the preceding year plus two or more of the Manning criteria.

\section{Results}

PREVALENCE OF SYMPTOMS OF IRRITABLE BOWEL SYNDROME

Of the 2280 questionnaires sent out, 1620 were returned and available for analysis, representing 785 men $(48 \%)$ and 835 women $(52 \%)$ and a response rate of $71 \%$. Of these 1620 respondents, $412(25 \%)$ had experienced six or more episodes of abdominal pain during the preceding year $(179(43 \%)$ men and 233 $(57 \%)$ women). A total of $350(85 \%)$ of these patients reported symptoms consistent with the diagnosis of irritable bowel syndrome, defined as abdominal pain plus two or more of the six cardinal symptoms defined by the Manning criteria, giving a one year period prevalence of irritable bowel syndrome of $21.6 \%$ overall, with prevalence figures of $18.7 \%$ for men and $24 \cdot 3 \%$ for women $(p<0 \cdot 01)$. Table I shows the prevalence of these symptoms in men and women by age. Frequency of symptoms was not related to social class and was unaffected by smoking habit. A total of 251 patients had abdominal pain plus three or more of Manning et al's cardinal criteria. Table II shows the distribution of these cardinal symptoms in the patients with irritable bowel syndrome; no notable differences exist between the prevalence of these symptoms in consulting and non-consulting subjects.

Diarrhoea and constipation were reported by $12 \%$ and $13 \%$, respectively, of the subjects without symptoms of irritable bowel syndrome; not surprisingly, $58 \%$ of patients with irritable bowel syndrome had diarrhoea and $48 \%$ had constipation. The overall prevalence of rectal bleeding in this study was $20 \%$; rectal bleeding was present in $10 \%$ (127) of the subjects without symptoms of irritable bowel syndrome and the passage of mucus per rectum in $7 \%$ (89) compared with $35 \%(123)$ and $32 \%(112)$ in patients with irritable bowel syndrome (table III). Only $51 \%$ (91) of the patients with irritable bowel syndrome and rectal bleeding reported the presence of haemorrhoids.

\section{ASSOCIATED SYMPTOMS}

Several other symptoms were found significantly more often in patients meeting diagnostic criteria for irritable bowel syndrome. Heartburn was present in $79 \%$ (277) compared with $24 \%$ (305) of patients without irritable bowel syndrome $(\mathrm{p}<0.001)$; dyspeptic symptoms of some kind were reported by over $90 \%$ (319) of the patients with the syndrome and were more frequent in patients whose abdominal pain was not relieved by defecation than in those in whom pain was relieved in this way $(31 \%(108) v 69 \%(242) ; \mathrm{p}<0.01)$. Autonomic symptoms such as flushing and sweating were reported in 54\% (189) of patients with irritable bowel syndrome compared with $23 \%$ (292) of those without the syndrome $(\mathrm{p}<0.001)$, migraine in $32 \%$ (112) compared with $18 \%(229)(\mathrm{p}<0.01)$, urinary symptoms in $34 \%$ (119) compared with $21 \%$ (266) $(\mathrm{p}<0.01) ; 18 \%$ (37) of women with irritable bowel

TABLE I-Prevalence and consultation rates by age for irritable bowel syndrome

\begin{tabular}{|c|c|c|c|c|c|c|c|c|c|c|c|c|c|c|c|c|}
\hline & \multicolumn{2}{|c|}{$20-29$} & \multicolumn{2}{|c|}{$30-39$} & \multicolumn{2}{|c|}{$40-49$} & \multicolumn{2}{|c|}{$50-59$} & \multicolumn{2}{|c|}{$60-69$} & \multicolumn{2}{|c|}{ 70-79 } & \multicolumn{2}{|c|}{$>80$} & \multicolumn{2}{|c|}{ Total } \\
\hline & Men & Women & Men & Women & Men & Women & Men & Women & Men & Women & Men & Women & Men & Women & Men & Women \\
\hline \multirow{3}{*}{$\begin{array}{l}\text { No of questionnaires returned } \\
\text { No }(\%) \text { with symptoms of } \\
\text { irritable bowel syndrome } \\
\text { No }(\%) \text { with irritable bowel } \\
\text { syndrome consulting GP }\end{array}$} & 89 & 92 & 120 & 137 & 150 & 161 & 142 & 130 & 153 & 140 & 106 & 116 & 25 & 59 & 785 & 835 \\
\hline & $26(29)$ & $25(27)$ & & $43(31)$ & $26(17)$ & $48(30)$ & & $29(22) 2$ & & $24(17)$ & $17(16)$ & $23(20)$ & $5(20)$ & $11(19)$ & $147(19)$ & $203(24)$ \\
\hline & $5(19)$ & $9(36)$ & $12(35)$ & $12(28)$ & $7(27)$ & $13(27)$ & $2(14)$ & $10(34) 1$ & $10(40)$ & $11(46)$ & $6(35)$ & $9(39)$ & $2(40)$ & $9(82)$ & $44(30)$ & $73(36)$ \\
\hline
\end{tabular}


TABLE II - Distribution of Manning criteria in subjects with six or more episodes of abdominal pain a year

\begin{tabular}{lcccc}
\hline & \multicolumn{5}{c}{ No (\%) of patients } \\
\cline { 2 - 5 } No of criteria present & Non-consulters & Consulters & Missing data & Total \\
\hline 0 & $17(6)$ & $5(4)$ & 1 & $23(5)$ \\
1 & $24(9)$ & $14(10)$ & 1 & $39(10)$ \\
2 & $66(25)$ & $30(22)$ & 3 & $99(24)$ \\
3 & $60(22)$ & $35(26)$ & 3 & $98(24)$ \\
4 & $52(20)$ & $29(21)$ & 2 & $83(20)$ \\
5 & $31(12)$ & $17(13)$ & 1 & $49(12)$ \\
6 & $15(6)$ & $6(4)$ & & $21(5)$ \\
\hline Total & 265 & 136 & 11 & 412 \\
\hline
\end{tabular}

TABLE III-Prevalence of symptoms in subjects with and without irritable bowel syndrome (IBS)

\begin{tabular}{lcc}
\hline & $\begin{array}{c}\text { No (\%) without IBS } \\
(\mathrm{n}=1270)\end{array}$ & $\begin{array}{c}\text { No (\%) with IBS } \\
(\mathrm{n}=350)\end{array}$ \\
\hline Diarrhoea & $152(12)$ & $203(58)$ \\
Constipation & $165(13)$ & $168(48)$ \\
Both & $64(5)$ & $95(27)$ \\
Neither & $1016(80)$ & $74(21)$ \\
Mucus in stool & $89(7)$ & $112(32)$ \\
Blood in stool & $127(10)$ & $123(35)$ \\
Both & $38(3)$ & $56(16)$ \\
Neither & $1092(86)$ & $172(49)$ \\
\hline
\end{tabular}

syndrome had had a hysterectomy compared with $12 \%$ (74) of those without the syndrome $(\mathrm{p}<0.05)$. Asthma was reported in $6 \%$ (21) of patients with irritable bowel syndrome and $8 \%(102)$ of those without the syndrome. A greater proportion of patients with irritable bowel syndrome used non-steroidal anti-inflammatory drugs (14\% (48) $v 9 \%$ (111); NS). The association between the syndrome and rectal bleeding was stronger in patients who reported non-colonic symptoms than those who did not $(65 \%$ (66) v 35\% (36); p <0.01). Abdominal pain in childhood was reported significantly more commonly by the patients with symptoms of irritable bowel syndrome (12\% (42) $v 3 \%$ (11); $\mathrm{p}<0 \cdot 001)$.

\section{CONSULTATION BEHAVIOUR}

Of the 350 patients meeting the diagnostic criteria for irritable bowel syndrome only 117 (33\%) had sought medical advice for these symptoms in the two years preceding completion of the questionnaire (table I). Overall, $30 \%$ of men (44) and $36 \%$ of women (73) had consulted their general practitioner; consultation rates rose progressively with patients' age but were also influenced by other factors, such as the patient's individual general practitioner and the presence of other symptoms. For example, the consultation rate for patients with symptoms of irritable bowel syndrome but no rectal bleeding was $25 \%$ whereas $47 \%$ of those with the syndrome and rectal bleeding had sought medical advice. Among patients aged 40-60 the prevalence of rectal bleeding was about $10 \%$, but not even a third of these had sought medical advice during the study period. Interestingly, symptom severity in irritable bowel syndrome, as judged by the number of Manning et al's cardinal symptoms present in addition to abdominal pain, was not associated with consultation behaviour. Consultation for these symptoms varied widely between the eight participating general practitioners, with a range in consultation rate from $18 \%$ to $38 \%$.

Self medication with a variety of over the counter aperients and bulking agents was reported by $39 \%$ (137) of the patients with irritable bowel syndrome compared with $17 \%(216)$ of those without the syndrome. A total of $49(14 \%)$ of the patients with irritable bowel syndrome had been referred to hospital by their general practitioners because of their symptoms.

\section{Discussion}

This study, using rigorous random sampling, has provided an accurate estimate of the prevalence of functional bowel disorders in the general population. The response rate in this study was $71 \%$, so that even if all the non-responding subjects had no symptoms of irritable bowel syndrome the minimum prevalence of the condition would be $15 \cdot 4 \%$, compared with our prevalence figure of $21.6 \%$ calculated on the basis of the 1620 replies to the questionnaire. Although it is possible that a "personal significance" bias was included in subjects' likelihood to return the questionnaire, there is evidence that most biases disappear when a response rate of $70 \%$ or more is achieved. ${ }^{22}$ The finding that almost a quarter of the community has experienced symptoms consistent with the diagnosis of irritable bowel syndrome is comparable to previous published work in the United Kingdom, Europe, and North America. ${ }^{3+22}$ The high prevalence of these symptoms in women, particularly those in their $30 \mathrm{~s}$ and $40 \mathrm{~s}$, reflects clinical experience, but the finding of a similar community prevalence of symptoms of irritable bowel syndrome in men and women, particularly in the 20-40 and over 60 age groups, is at odds with traditional teaching that the syndrome is a condition predominantly experienced by women. ${ }^{22}$ Consultation behaviour largely explains this observation.

The high prevalence of other symptoms such as diarrhoea and constipation is not surprising, but this study has shown for the first time that rectal bleeding, as well as the passage of mucus, is more commonly experienced by patients with symptoms of irritable bowel syndrome. The overall one year period prevalence of rectal bleeding of $20 \%$ in this study is comparable with a figure of $16 \%$ reported in an Australian study in 1986. ${ }^{23}$ Although rectal bleeding is commonest in patients in the $20-40$ age group, the finding of a $10 \%$ prevalence of rectal bleeding in middle aged patients, accompanied by a low consultation rate, is worrying. It suggests that some patients with symptoms that may indicate serious bowel disease are not seeking appropriate medical attention and also confirms similar findings reported in a small survey of middle aged and elderly adults in $1986 .{ }^{24}$ Because of the low prevalence of inflammatory bowel disease in the community it is unlikely that the inclusion of patients with this condition has significantly biased these observations.

We have confirmed in this study the association between symptoms compatible with a clinical diagnosis of irritable bowel syndrome and other symptoms that may reflect smooth muscle dysfunction. In particular, autonomic symptoms such as flushing and sweating, migraine, urinary symptoms, and gynaecological problems are all significantly more common in the group with irritable bowel syndrome, although we are unable to confirm an association with asthma; this may be related to the design of our questionnaire, which did not explore in detail the prevalence of respiratory symptoms or the use of asthma drugs. Whether this association between symptoms reflects an underlying smooth muscle disorder is still a matter for speculation. As in our previous study of dyspepsia ${ }^{5}$ we have shown how patients' consultation behaviour is partly determined by their general practitioners, with wide variations between consultation rates with different general practitioners. These differences cannot be explained by demographic differences in the practices. The relationship between patient and doctor and the expectations engendered therein are obviously important determinants of patients' decisions to seek medical attention and deserves further study.

In summary, this report shows that symptoms of irritable bowel syndrome are common in the general population and that only a minority of patients seek 
Centre for Research on

Drugs and Health Behaviour, Charing Cross and Westminster Medical School, London SW6 1RQ Paul J Turnbull, BA, research worker

Gerry V Stimson, MRCPSYCH, professor

Kate A Dolan, BSC, research fellow

Correspondence to: Mr Turnbull.

BMf 1992;304:90-1 medical advice for them. Men as well as women often experience these symptoms, and consultation behaviour is likely to explain previous assertions that irritable bowel syndrome is experienced predominantly by women. The patients with the syndrome reported here also had rectal bleeding much more commonly than subjects without the syndrome, but consultation rates for rectal bleeding are also low.

We still have a poor understanding of the triggers to consultation among these patients. Studies from North America have reported that psychopathology is more frequent in consulting than non-consulting patients with irritable bowel syndrome but is not a feature of the syndrome itself. ${ }^{1725}$ More research is required to clarify patients' reasons for seeking medical advice and their expectations of their medical attendants so that the clinical care of patients with these common symptoms can be improved.

We thank all the participating general practitioners and their patients for their cooperation, the Scientific Foundation Board of the Royal College of General Practitioners and Duphar Laboratories Ltd for their support, and Professor Michael Farthing for helpful suggestions.

1 Mitchell CM, Drossman DA. Survey of the AGA membership relating to patients with functional gastrointestinal disorders. Gastroenterology 1987;92: patients

2 Ingham JG, Miller PM. Symptom prevalence and severity in a general practice population. 7 Epidemiol Commun Health 1979;33:191-8.

population. $\mathrm{F}$ Epidemiol Commun Health 1979;33:191-8.
Drossman DA, Sandler RS, McKee DC, Lovitz AJ. Bowel patterns among subjects not seeking health care. Gastroenterology 1982;83:529-34.

4 Thomson WG, Heaton KW. Functional bowel disorders in apparently healthly people. Gastroenterology 1980;79:283-8.

5 Jones RH, Lydeard SE. Prevalence of symptoms of dyspepsia in the community. BM 1989;298:30-2.

6 Lydeard SE, Jones RH. Factors affecting the decision to consult with dyspepsia: comparison of consulters and non consulters. $\mathcal{F} R$ Coll Gen Pract 1989;39:495-8.

\section{Prevalence of HIV infection among ex-prisoners in England}

\section{Paul J Turnbull, Gerry V Stimson, Kate A Dolan}

7 Manning AP, Thompson WG, Heaton KW, Morris AF. Towards positive diagnosis of the irritable bowel. BMF 1978; ii: $653-4$.

8 Thompson WG. Gastrointestinal symptoms in the irritable bowel compared with peptic ulcer and inflammatory bowel disease. Gut 1984;25:1089-92.

9 Talley NJ, Phillips SF, Melton LJ, Mulvihill C, Wiltgen C, Zinsmeister AR. Diagnostic value of the Manning criteria in irritable bowel syndrome. Gut 1990;31:77-81.

10 Smith RC, Greenbaum DS, Vancouver JB, Henry RC, Reinhart MA, Greenbaum RB, et al. Gender differences in Manning criteria in irritable bowel syndrome Gastroenterology 1991;100:591-5.

11 Whorwell PJ, Lupton EW, Erduran D, Wilson K. Bladder smooth muscle abnormalities in patients with irritable bowel syndrome. Gut 1986;27: 1014-7.

12 Sandler RS, Drossman DA, Nathan H. Symptom complaints and health care seeking behaviour in subjects with bowel dysfunction. Gastroenterology $1984 ; 87: 314-8$.

13 Whorwell PJ, McCallum M, Creed FH, Roberts TC. Non-colonic features of irritable bowel syndrome. Gut 1986;27:37-40.

14 White AM, Stevens WH, Upton AR, O'Byrne PM, Collins SM. Airway responsiveness to inhaled methacholine in patients with irritable bowel syndrome. Gastroenterology 1991;100:68-74.

15 Isgar B, Harman M, Kaye MD, Whorwell PJ. Symptoms of irritable bowel syndrome in ulcerative colitis in remission. Gut 1983;24:190-1.

16 Heaton KW, Ghosh S, Braddon FEM. How bad are the symptoms and bowel dysfunction of patients with irritable bowel syndrome? Gut 1991;32:73-9.

7 Smith RC, Greenbaum DS, Vancouver JB, Henry RC, Reinhart MA,

Greenbaum RB, et al. Psychological factors are associated with health care Greenbaum RB, et al. Psychological factors are associated with health care seeking rather than

18 Talley NJ, Phillips SF, Bruce B, Twomey CK, Zinsmeister AR, Melton LJ. Relation among personality and symptoms in non-ulcer dyspepsia and the Relation among personality and symptoms in non-ulcer dy
irritable bowel syndrome. Gastroenterology 1990;99:327-33.

19 Bordie AK. Functional disorders of the colon. F Indian Med Assoc 1972;58: $451-5$.

20 Mendis BLJ, Wijesiriwardena BC, Sheriff MHR, Dharmadason K. Irritable bowel syndrome. Ceylon Med $\mathcal{F}$ 1983;27:171-81.

21 Goudy WJ. Interim response to a mail questionnaire: impacts on variable relationships. Iowa State University, 1976. (Iowa Agriculture and Home Economics Experiment State journal paper No 3.)

22 Thompson WG. Gut reactions: understanding symptoms of the digestive tract. London: Plenum, 1989.

23 Dent OF, Goulston KJ, Zobrzyck J, Chapuis PH. Bowel symptoms in an apparently well population. Dis Colon Rectum 1986;29:243-7.

24 MacDonald L, Freeling P. Bowels: beliefs and behaviour. Family Practice 1986;3:80-4

25 Drossman DA, McKee DC, Sandler RS, Mitchell CM, Cramer EM, Lowman $\mathrm{BC}$, et al. Psychosocial factors in the irritable bowel syndrome: a multivariate study of patients and non-patients with irritable bowel syndrome. Gastroenterology 1988;95:701-8.

(Accepted 1 October 1991)

( $55 \%$ had served over 12 months). Risk behaviour data are reported elsewhere. ${ }^{3}$

Saliva samples were collected from 402 subjects. Positive results for HIV antibodies were obtained in 19 and negative results in 366 (17 samples were too small to test). The largest proportion of people who were HIV positive was found in the injecting group at $10 \cdot 1 \%$ (table I); the rate for women who injected $(15.5 \%)$ was twice that for men. Rates of HIV infection were relatively low in other groups, but HIV infection was found among non-injecting heterosexual men and noninjecting women. HIV infection in these samples may indicate possible heterosexual transmission or transmission via blood products, but earlier unsafe injection or homosexual behaviour cannot be excluded as a risk factor.

Ex-prisoners in England: results of testing saliva samples for HIV antibodies

\begin{tabular}{|c|c|c|c|}
\hline \multirow[b]{2}{*}{ Group } & \multirow[b]{2}{*}{ No tested } & \multicolumn{2}{|c|}{ HIV antibody positive } \\
\hline & & No (\%) & $\begin{array}{l}95 \% \text { Confidence } \\
\text { interval }(\%)\end{array}$ \\
\hline Injectors: & 148 & $15(10 \cdot 1)$ & $5 \cdot 3$ to 14.8 \\
\hline Men & 103 & $8(7 \cdot 7)$ & 2.6 to 12.8 \\
\hline Women & 45 & $7(15 \cdot 5)$ & $5 \cdot 0$ to $26 \cdot 0$ \\
\hline $\begin{array}{l}\text { Non-injecting } \\
\text { women }\end{array}$ & 29 & $1(3 \cdot 4)$ & -3.1 to 9.9 \\
\hline $\begin{array}{l}\text { Homosexual/bisexual } \\
\text { men }\end{array}$ & 20 & $\begin{array}{l}0 \\
3(1 \cdot 6)\end{array}$ & \\
\hline Others & 188 & & $-0 \cdot 1$ to $3 \cdot 3$ \\
\hline
\end{tabular}
hundred and seventy one were men, and ages ranged from 14 to 62 with a mean of 27 years. The sample was not randomly selected, but was similar to the prison population in the proportion on remand $(20 \%)$ and the type of sentences. Between them the respondents had been in at least $63 \%$ of prisons and young offenders' institutions in England and Wales. Our sample underrepresented people who had served short sentences

\section{Comment}

Our group of subjects was similar to the general prison population in several characteristics and allows some provisional estimate of the prevalence of HIV in prison. Extrapolation from the data of Maden et al 